\title{
Ativismo político negro \\ e o populismo em São Paulo
}

\section{Black Political Activism and Populism in São Paulo}

\section{JoÃo Batista Nascimento GREGOIRE*}

Obra resenhada:

DOMINGUES, Petrônio. Estilo Avatar: Nestor Macedo e o populismo no meio afro-brasileiro. São Paulo: Alameda Casa Editorial, 2018. 265p.

Uma parte relevante, porém ignorada de nossa história, é recuperada habilmente por Petrônio Domingues em sua mais recente obra. Domingues tem-se destacado como um historiador comprometido em expandir o entendimento do multifacetado papel do negro na construção da sociedade brasileira. Um dos maiores estudiosos da história do ativismo negro político, o autor se posiciona contrário ao discurso convencional que situa o negro brasileiro como relevante agente cultural, mas que não atribui a mesma significância à atuação negra na história política, econômica e social. Domingues, em Estilo Avatar, traz uma essencial contribuição para retificar essa narrativa.

A escolha de pesquisar uma organização até então pouco conhecida, a Ala Negra Progressista, organização fundada e liderada por

\footnotetext{
* https://orcid.org/0000-0002-3827-4184

University of Kansas, History Department

1450 Jaywak Blvd, 66045, Laurence, Kansas, United States

joaogregoire@ku.edu
} 
Nestor Macedo em São Paulo, no ano de 1948, constitui-se em uma das fortalezas do livro. Através deles, Domingues expõe a ignorância que permeia a sociedade brasileira sobre a multiplicidade e complexidade do papel do negro no âmbito político brasileiro. Domingues ressalta que, apesar de serem ativos participantes do processo democrático, Nestor Macedo e a Ala Negra Progressista nunca receberam atenção da literatura especializada e jamais foram objetos de uma pesquisa acadêmica. Tal observação reforça a relevância dos estudos históricos em promover narrativas de inclusão. Enquanto muito da literatura sobre populismo no Brasil tem se concentrado apenas em lideranças brancas, Estilo Avatar reverte o foco e investiga a dimensão das práticas populistas na população afro-brasileira.

Esse trabalho se junta a uma literatura emergente que se dedica a compreender a trajetória histórica do negro na política brasileira. As recentes pesquisas acadêmicas de Edilza Sotero (2015), Tianna Paschel (2018), Gladys Mitchell (2018) e Kwame Dixon (2016) comprovam que a rica, porém ainda pesquisada em estágio incipiente, história afro-brasileira no mundo político é pontuada por uma mobilização determinada, intelectualmente centrada e imbuída de profunda consciência política.

Estilo Avatar vai além da missão de resgatar esse importante e olvidado fragmento da história brasileira. As correções metodológicas e teóricas no campo de Black Studies que visam retificar narrativas históricas que, por longo período, colocaram o negro como sujeito passivo na construção histórica, são habilmente executadas em Estilo Avatar (DAGBOVIE, 2015). A análise de Domingues da sinuosa relação entre Nestor Macedo e um dos expoentes do populismo político brasileiro, o governador paulista Adhemar de Barros, serve de advertência a historiadores para a diferença entre assimetria de poder e completa subjugação. Ao mesmo tempo que o autor não esconde o fato de Adhemar de Barros gozar de reconhecimento e poder político superiores aos de Nestor Macedo, ele salienta que ambos constantemente negociavam e buscavam, através de sua associação, o alcance de seus objetivos particulares.

O primeiro capítulo traça as origens da ANP. A ascendência da organização é contextualizada na atmosfera política vivida em São Paulo 
nos anos pós-Estado Novo. É nesse ambiente de retomada democrática que Adhemar de Barros se estabelece como liderança política e expoente do populismo no estado de São Paulo. Domingues define o processo de construção do "mito Adhemar Barros" como um projeto político que focava numa interlocução direta com as massas, apoiada por um grupo de profissionais de propaganda e uso massivo da mídia, "recorrendo ao rádio, ao cinema, à música e a imprensa" (p. 55) para conduzir sua campanha eleitoral. Domingues nota que a "Ala Negra Progressista inscrevia em capítulos, artigos e parágrafos dos seus estatutos a preocupação com o negro no mundo da política” (p. 48). Convencionalmente, considera-se que houve um hiato na história do ativismo negro político no período entre o abrupto fim da Frente Negra Brasileira em 1937 e o advento do Movimento Negro Unificado em 1978. O autor parcialmente diverge de tal narrativa e nos mostra, através do caráter político da Ala Negra Progressista, que o negro brasileiro nunca deixou de aspirar a um papel de protagonista na política brasileira. Além da relevância histórica da ANP por ter sido uma organização negra que objetivava a inserção da comunidade afro-brasileira no mundo político, a ANP também desempenhava um relevante papel no fomento da conscientização racial. Tal mobilização se articulava principalmente através de "panfletos, palestras, encontros e reuniões sociais" (p. 50). O livro também singulariza o engajamento de lideranças femininas que, através de uma Diretiva Feminina, conduziram diversas atividades de cunho social. Ademais, nesse capítulo o autor destaca a constante negociação entre a classe política e a operária, ressaltando a assimetria de poder entre as partes sem a plena submissão do grupo subalterno. Domingues demonstra que a elite política, embora fizesse uso da máquina eleitoral para se manter no poder, era também alvo da pressão da classe trabalhadora, estabelecendo assim entre as partes uma "relação de negociação e conflito por uma via de mão dupla” (p. 74).

O capítulo seguinte foca no personagem histórico central da obra de Domingues, Nestor Macedo. Os arquivos do Deops possibilitaram ao autor revelar fragmentos da vida social e ativista de Nestor Macedo e sua organização. A ANP não passou incólume frente ao ostensivo 
monitoramento do Deops de qualquer movimento social, cultural ou político que pudesse representar potencial ameaça à ordem política. A rigorosa investigação conduzida por Domingues nos apresenta na figura de Macedo um personagem riquíssimo, que acima de tudo, aprendeu a lidar com os meandros da política e sociedade brasileira para lutar por uma posição de protagonismo.

O autor nos revela que Adhemar de Barros e Nestor Macedo eram produtos de similar estirpe política que sorviam das práticas populistas para avançar suas agendas. Enquanto Adhemar de Barros usava dos palanques políticos e da máquina eleitoral para consolidar sua carreira política e permutar favores, Nestor Macedo ficou conhecido como o "Rei dos bailes", dada sua estratégia de promover atividades festivas no salão de baile da ANP, e assim sedimentar sua influência na comunidade negra.

Em relação ao personagem principal do livro, Domingues em momento algum romantiza a personalidade de Nestor Macedo como articulador político e ambicioso líder negro, assim como nunca a deprecia por suas falhas e dúbias condutas que por vezes tiveram desfecho em uma delegacia. Domingues expõe tanto as virtudes como as defecções desse personagem complexo. O autor salienta que ao mesmo tempo que Macedo "não se importava de colaborar com o Deops e tampouco tinha por isso crise de consciência” (p. 98), ele também via a política como instrumento de justiça racial, e através desse meio reivindicava benefícios para sua comunidade.

O último capítulo examina como a ANP capitalizou dos ares democráticos que alentavam a comunidade negra a demandar a inclusão da questão racial nas agendas das lideranças político-partidárias. Esse capítulo foca em uma das perguntas fundamentais abordadas no livro. Por que Nestor Macedo e a Ala Negra Progressista optaram por apoiar Adhemar de Barros? Domingues argumenta que, apesar de algumas demonstrações de solidariedade à população negra, para Adhemar a questão racial era de secundária importância.

Para Domingues, a razão da aproximação de Adhemar junto aos votantes negros era fundamentalmente "um investimento de 
engenharia política, de quem não desperdiçava a oportunidade de explorar o potencial eleitoral dos segmentos específicos da população" (p. 164). Domingues atribui grande peso à associação entre Nestor Macedo e Adhemar de Barros à negligência dos atores políticos, tanto da esquerda quando da direita, quanto à questão racial durante as décadas de 1940 e 1950 (ANDREWS, 1991; HANCHARD, 1994). Dessa forma, o populismo ademarista "mesmo que de forma oportunista, instrumental e frívola” (p. 227), destacava-se por incluir a questão racial em sua plataforma política. Com a consolidação democrática das últimas décadas na América Latina, a questão da maior integração política de grupos subalternos começou a receber maior atenção por parte do meio acadêmico. Estudos históricos como Estilo Avatar nos possibilitam traçar a trajetória do laborioso processo que tais minorias enfrentaram para conscientizar lideranças políticas brasileiras sobre a questão racial.

É imperativo que pesquisadores deem a devida atenção à estrutura político-partidária de cada contexto político, a fim de compreender a razão pela qual certos grupos negros empregaram seu apoio político a partidos que atribuíam pouca relevância à questão racial. Se a congruência ideológica não se estabeleceu como agente agregador entre tais associações, elas não se constituem em anomalias políticas, mas sim obedecem o comportamento de grande parte das alianças partidárias no meio político brasileiro, onde grupos políticos ideologicamente díspares se aliam para avançar seus específicos projetos de poder, estabelecendo assim "a política da permuta" (p. 94).

Estilo Avatar é leitura obrigatória para qualquer leitor interessado em expandir seu conhecimento sobre o protagonismo negro no projeto de nação brasileira. O resgate histórico de Nestor Macedo e sua organização corrigem a narrativa prevalente que o populismo no Brasil se restringiu a lideranças brancas como Getúlio Vargas e Adhemar de Barros, que cooptaram e subjugaram a população negra. Estilo Avatar deve servir como um trecho de um caminho longo a ser percorrido pela historiografia das relações raciais no Brasil. Indubitavelmente temos muito a aprender sobre a população afro-brasileira no populismo, e que a obra de Domingues sirva de inspiração para futuras pesquisas acadêmicas. 
De igual importância é a correção metodológica apresentada no livro que necessita ser salientada e reiterada para futuras investigações históricas de grupos subalternos. Vindouras pesquisas acadêmicas sobre as experiências da população afro-brasileira têm a missão e a responsabilidade de abdicar de classificar o negro brasileiro como ator anônimo ou secundário, e sim retratá-lo como agente central e ativo da história brasileira.

\section{REFÊRENCIAS BIBLIOGRÁFICAS}

ANDREWS, George Reid. Blacks and Whites in São Paulo 1888 - 1988. Madison: The University of Wisconsin Press, 1991.

DAGBOVIE, Pero Gaglo. What is African American History? Malden: Polity Press, 2015.

DIXON, Kwame. Afro-politics and Civil Society in Salvador da Bahia, Brazil. Gainesville: University Press of Florida, 2016.

DOMINGUES, Petrônio. Estilo Avatar: Nestor Macedo e o populismo no meio afro-brasileiro. São Paulo: Alameda Casa Editorial, 2018.

HANCHARD, Michael George. Orpheus and Power: The Movimento Negro of Rio De Janeiro and São Paulo, Brazil, 1945-1988. Princeton: Princeton University Press, 1994.

MITCHELL, Gladys L. The Politics of Blackness: Racial Identity and Political Behavior in Contemporary Brazil. New York: Cambridge University Press, 2018.

PASCHEL, Tianna S. Becoming Black Political Subjects: Movements and Ethno-racial Rights in Colombia and Brazil. Princeton: Princeton University Press, 2018.

SOTERO, Edilza. Representação política negra no Brasil pós Estado Novo. Tese (Doutorado em Sociologia) - Universidade de São Paulo, São Paulo, 2015. 